\title{
Study on Cutting Form and Surface Machining Quality of Wheel Tread under Reprofiling
}

\author{
Jianxi Wang, ${ }^{1,2}$ Xin Xue, ${ }^{3}$ and Yongjie $\mathrm{Lu}^{3}$ \\ ${ }^{1}$ School of Civil Engineering, Shijiazhuang Tiedao University, Shijiazhuang 050043, China \\ ${ }^{2}$ Key Laboratory of Road and Railway Engineering Safety Control of Ministry of Education, \\ Shijiazhuang Tiedao University, Shijiazhuang 050043, China \\ ${ }^{3}$ School of Mechanical Engineering, Shijiazhuang Tiedao University, Shijiazhuang 050043, China
}

Correspondence should be addressed to Yongjie Lu; lu-yongjie@163.com

Received 4 November 2016; Accepted 29 March 2017; Published 28 June 2017

Academic Editor: Paolo Ferro

Copyright (C) 2017 Jianxi Wang et al. This is an open access article distributed under the Creative Commons Attribution License, which permits unrestricted use, distribution, and reproduction in any medium, provided the original work is properly cited.

\begin{abstract}
The wheelset maintenance cost is an important part of train maintenance cost. Researchers and railway operators have been closely concerned about the way to minimize residual stress at wheel tread and surface roughness during wheel reprofiling, thereby reducing the wheel damage during operation, extending the wheelset service life, and cutting down wheelset maintenance cost. The present study involves dynamic simulation of tread reprofiling process by building a finite element model of wheel reprofiling, taking the wheel steel as research object. This paper makes a comprehensive analysis of surface roughness and residual stress distribution of wheel tread under different milling parameters. The simulation results indicate that the increase in cutting speed and back cutting depth causes the chip morphology to change while impairing the machined surface quality. Once serrated chip occurs, it means wheel tread machining quality deteriorates remarkably. In this way, the paper associates macroscopic chip morphology with microcosmic surface roughness and internal residual stress to provide theoretical basis for optimization of wheel reprofiling process.
\end{abstract}

\section{Introduction}

High speed railway and urban rail transit have been mushrooming in China since 2010 and are now ushering in an overhaul period, in view of which the branches of China Railway Corporation carried out parts and accessories replacement and maintenance for motor train units and other types of trains. When a train travels on rails, all its load is applied to bogie wheelset; due to the complex contact force between wheelset and rails, the wheel tread and flange may develop different degrees of damage after certain mileage; since the worn train wheels immediately affect train operation quality (stability, safety, and passenger comfort) and service life of rails [1-3], the reprofiling of worn wheels is considered an important part of maintenance of trains in service [4]; the maintenance of wheelsets is expensive; for example, the rolling circle diameter of new wheelset for Guangzhou Metro is $840 \mathrm{~mm}$; the price of a semifinishing wheel is RMB 6,500, and the finishing expense and freight per wheelset is about RMB 9,000; that is to say, every $1 \mathrm{~mm}$ of decrease in wheelset diameter would cost nearly RMB 550. In consideration of the fact that Guangzhou Metro has 60 passenger trains, each of which is furnished with 24 wheelsets, every $1 \mathrm{~mm}$ of reduction in wheel diameter costs RMB 420,000 in total [5]; to this end, it is of great economic significance to improve reprofiling quality; by reason that maintenance peak has not yet appeared, more and more challenges will come out in terms of operation and maintenance of rail transit. Reprofiling is normally performed to restore the geometry of wheel tread for purpose of maintenance, but maintenance data investigation showed that the quantity of useful metal cut-off during the reprofiling of wheelset tread is much greater than the abrasion-induced metal loss during operation. Some scholars carried out studies on wheel reprofiling strategy and profile optimization design; Zhang et al. proposed a multiobjective optimized reprofiling model that helped to reduce reprofiling 
quantity and made it possible for wheels with abrasion loss to attain comprehensive performance of master profile without the realization of master profile, thereby extending their service life [6]. Chien et al. studied wheel wear statistical data processing method based on mathematical statistics and built a wheel reprofiling period prediction model [7]. Extensive research has been conducted on the management, reprofiling quantity, and cost-effective reprofiling of wheel tread in Japan $[8,9]$.

The generation process of residual stress is extremely complicated during wheel reprofiling; it affects the surface machining quality of tread and the practical performance and lifetime of wheelset [10]. Residual stress principally results from mechanical stress-induced plastic deformation, thermal stress-induced plastic deformation, and microstructure change-induced plastic deformation. Wang and Liu gave a general description of the production mechanism of residual stress during cutting process and conducted comprehensive comparison in terms of residual stress measuring technique and elimination method [11]. Sasahara et al. used elasticplastic metal cutting finite element model to simulate the distribution of residual stress and residual strain at machined surface during continuous cutting at low speed [12]. Seo et al. revealed the mapping relationship between residual stress and wheel fatigue during the manufacturing and train braking of wheel through experiment and finite element simulation [13]. Hiroyuki et al. studied the impact of residual stress resulting from different machining parameters on part fatigue strength [14]. Nejad et al. analyzed the residual stress distribution after the heat treatment of the wheel and studied the effect of residual stress on fatigue crack propagation. It was found that the residual stress had a great effect on the rate of crack propagation $[15,16]$. Paul and Adam analyzed the changes of residual stress in railway wheel during its life and its relationship with wheel tread contact fatigue damage. It was found that the residual stress distribution of wheel during its life was changed and the residual stress was relatively big, exceeding the specification [17].

With respect to metal cutting simulation, some researchers in Japan and the Soviet Union developed some finite element models for metal cutting and performed finite element analysis as far back as the 1970s. Usui et al. employed Coulomb friction model for contact surface between cutter and chip and simulated the production process of builtup edge during metal cutting using finite element method [18]. Strenkowski and Moon used Eulerian finite element model for metal cutting to simulate the shape of chip during metal cutting and studied the temperature field distribution in workpiece, cutter, and chip in the case of orthogonal cutting; however, this model is not applicable for analysis of initial chip shaping stage [19]. Zhang carried out a thorough research on chip separation criterion in orthogonal cutting process through finite element model for metal cutting and performed analysis and research on separation criteria under different conditions [20]. Sun et al. performed nonlinear elastic-plastic finite element simulation analysis for cutting process of aerial aluminum alloy, as well as prediction and calculation of residual stress at cutting surface through coupled thermomechanical three-dimensional finite element model [21].

With respect to wheel tread reprofiling process, many scholars have carried out related research. Seo et al. studied effects of metal removal and residual stress on the contact fatigue life of railway wheels by applying finite element analyses and conducting corresponding fatigue test. The results showed that the residual stress determined the amount of metal removal depth for the optimal fatigue life and an equation was proposed to calculate the optimal metal removal depth for maximizing the contact fatigue life [13]. Resilient wheels are made to reduce noise and improve comfort of travelling with lightweight railways. This solution may be a problem during turning of such wheelset on axle turning lathes. The biggest problem in turning resilient wheelsets on wheel-turning lathes with friction drive appears to be axial deformation of wheel during the machining process. Filipowicz et al. used a FEM model to check if turning of resilient wheelsets on friction drive lathe is possible. The results showed that although cutting forces are very high, values of radial displacement are not big, and they do not have influence on geometry of machined tyre, especially while turning [22]. There are many different types of milling cutters for wheel tread reprofiling. There is a problem for how to choose a reasonable milling cutter to reduce processing costs at wheel tread reprofiling. Based on the experimental research, Tian analyzed the difference of the total using cost of different milling cutters and provided the theoretical basis for the economic selection of milling cutters [23]. Cioboata et al. presented some considerations on the development of a technological system for profiling/reprofiling and measurement of the profile of the railway wheel sets in order to improve maintenance of railway transport [24]. Andrade and Stow assessed the technical efficiency of different operators turning railway wheelsets on an underfloor wheel lathe using a stochastic frontier analysis, while controlling for other explaining variables such as the flange thickness and the occurrence of rolling contact fatigue defects, wheel flats, and cavities [25].

Researchers have so far made a great deal of research and got lots of achievements in respect of wheel profile optimization, chip formation mechanism, machined surface, cutting heat and cutting force, and so forth during metal cutting. However, extensive consultation showed that only a few literatures probed into cutting issues of wheel tread reprofiling. Locomotive researchers and railway operators should always bear in mind the way to reduce residual stress at wheel tread and surface roughness and wheel damage during wheel tread reprofiling and avoid frequent reprofilinginduced premature scrapping of wheels, thereby extending the life cycle of wheelsets and minimizing the wheelset maintenance cost. This paper probes into the wheel cutting chip forming mechanism, the residual stress distribution at wheel tread, and the surface roughness of wheel tread under different reprofiling parameters through numerical simulation analysis of wheel reprofiling process by dint of finite element-based research method. 
TABLE 1: Material parameters.

\begin{tabular}{lccccc}
\hline Temperature $/{ }^{\circ} \mathrm{C}$ & Thermal conductivity $/ \mathrm{W} \cdot \mathrm{m}^{-1} \cdot \mathrm{k}^{-1}$ & Temperature $/{ }^{\circ} \mathrm{C}$ & Expansion coefficient $/{ }^{\circ} \mathrm{C}^{-1}$ & Yield stress $/ \mathrm{MPa}$ & $\mathrm{Plastic}$ strain \\
\hline 290 & 48.46 & 230 & 0.0000108 & 989 & 0 \\
400 & 43.79 & & 0.0000131 & 1119 & 0.042 \\
\hline 493 & 38.65 & 567 & & 1190 \\
593 & 34.31 & & & 1236 & 0.092 \\
703 & 30.21 & & 0.0000137 & 1282 & 0.192 \\
800 & 25 & 773 & & 1298 & 0.272 \\
893 & 23.07 & & & \\
\hline
\end{tabular}

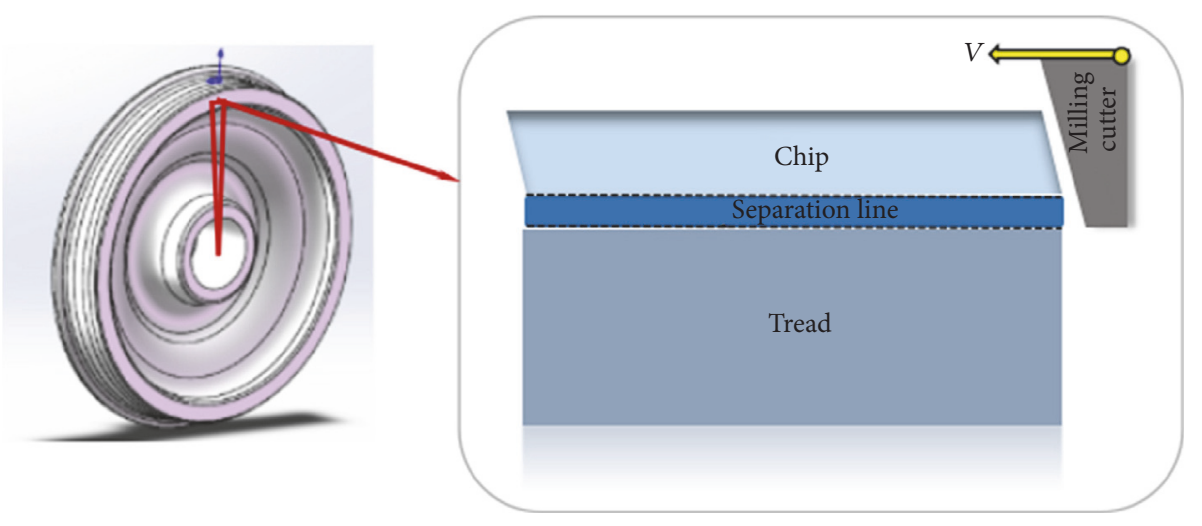

Figure 1: Wheel tread model simplification.

\section{Simplification and Building of Wheel Tread Reprofiling Model}

2.1. Simplification of Wheel Tread Reprofiling Model. The simulation would be extremely difficult when taking the entire actual wheel as reprofiling simulation object for finite element analysis, and any improper handling may bring about calculation failure or obvious error in calculation result. In such a case, the model could be simplified through reasonable hypothesis for convenient processing and calculation. The model could be considered to be in plane strain state when the width of cut metal is not less than 5 times the metal cutting thickness during cutting process. The use of a separation line in simplified wheel tread reprofiling model enables more accurate separation of chip from workpiece, thereby pushing simulation closer to practical machining [26]. The wheel tread reprofiling model simplification process is shown in Figure 1.

Thermal-mechanical coupled finite element model for wheel tread reprofiling is built based on the following assumptions: (1) cutting tool is a rigid object, for which only temperature properties are taken into account; (2) ignore the temperature change-induced microstructure change; (3) the material of machined material is isotropous; (4) take no account of the vibration of cutter and workpiece; (5) use plane strain model.

2.2. Definition of Workpiece Material. The metal cutting process of wheel reprofiling is seen as a process that develops great plastic deformation and the separation of chip from tread. The surficial metal of tread develops elastic-plastic deformation during wheel reprofiling; under the action of cutter, the cut material turns into chip within short time. The heterogeneous distribution of stress, strain, and temperature occurs at each point of the cut layer, and there exists significant gradient change. This generates much heat, thereby causing significant plastic deformation. From this point of view, the definition of material property shall reflect the effect of temperature, strain, and strain rate on material stress. For wheel tread material, wheel tire is made from high carbon steel with a carbon content of $0.60 \%-1.70 \%$; the material density is $7810 \mathrm{~kg} / \mathrm{m}^{3}$; its material behaviors include elasticity, plasticity, and expansion coefficients in respect of mechanics; its thermology includes conductivity, specific heat, and inelastic heat (refer to Table 1). The material for connection line additionally defines shear damage in ductile metal damage mechanically and defines an extremely small value ( $4 \times 10^{-6} \mathrm{~m}$, i.e., approx. half of the grid cell length) for equivalent plastic failure displacement; in the subsequent machining process, the separation line component enables the separation of chip from workpiece surface with the advance of cutter.

2.3. Adaptive Meshing of Reprofiling Model. Metal material is subjected to plastic flowage in some areas that change dramatically, for example, the metal chip, contact plane, and glide plane of large deformation, during finite element 
simulation of wheel reprofiling. With the increasing surrounding metal deformation, some meshes get squashed or develop serious deformation, which seriously affect calculation accuracy, result in serious distortion of calculation result, or even may frequently lead to negative Jacobi matrix, thereby causing calculation error and computing interruption. When adaptive mesh method is employed in these areas, the constant adjustment of mesh during iteration brings about mesh refinement, which enables the coupling of mesh point distribution to physical solution, thereby improving the solution accuracy and resolution. Automatic generation of meshes is roughly divided into structured mesh generation and unstructured mesh generation. This paper deals with structured mesh generation by defining many substructure generating meshes for uniform distribution of meshes (see Figure 2 for detailed process).

The finite element simulation of wheel tread reprofiling is a process of large deformation; the automatic local meshing during calculation with adaptive meshing in finite element software ABAQUS helps to improve the judgment accuracy of machined surface quality for wheel tread, save much computation time, and assure the accuracy of key part calculation.

\subsection{Cutter-Chip Interface Friction and Chip Separation Dis-} crimination Model. The contact surface friction during wheel tread reprofiling consists of two parts, that is, the friction between rake face and workpiece and that between flank face and machined surface. The friction area between rake face and chip falls into bond area and slide area. Hence, this paper first defines the contact properties between bottom face and right side of chip layer and separation line top face and between workpiece layer top face and separation line bottom face; the friction formula of tangential behavior is "roughness," while the pressure interference of normal behavior is "hard contact," where separation after contact is not allowable; then, the paper defines the contact properties between bottom face and right side of chip layer and cutter surface; the friction formula of tangential behavior is "penalty function," and the pressure interference of normal behavior is "hard contact," where separation after contact is allowable, while the definition of heat conduction is consistent with above-noted contact properties; finally, the paper defines the contact properties between workpiece layer top face and bottom face and right side of chip layer and cutting layer surface self-contact; the friction formula of tangential behavior is "penalty function," and the pressure interference of normal behavior is "hard contact," where separation after contact is allowable. According to Zorev's research findings [26], the normal stress and friction stress distribution during metal cutting is as shown in Figure 3.

The separation of chip from workpiece in finite element simulation of cutting process is normally judged based on appropriate criteria, that is, geometric criteria and physical criteria. According to geometric separation criterion, the software identifies material separation when the distance from rigid cutter tip to the element node in its front along the predetermined machining path is less than a predetermined threshold. The upper node moves upward along rake face,

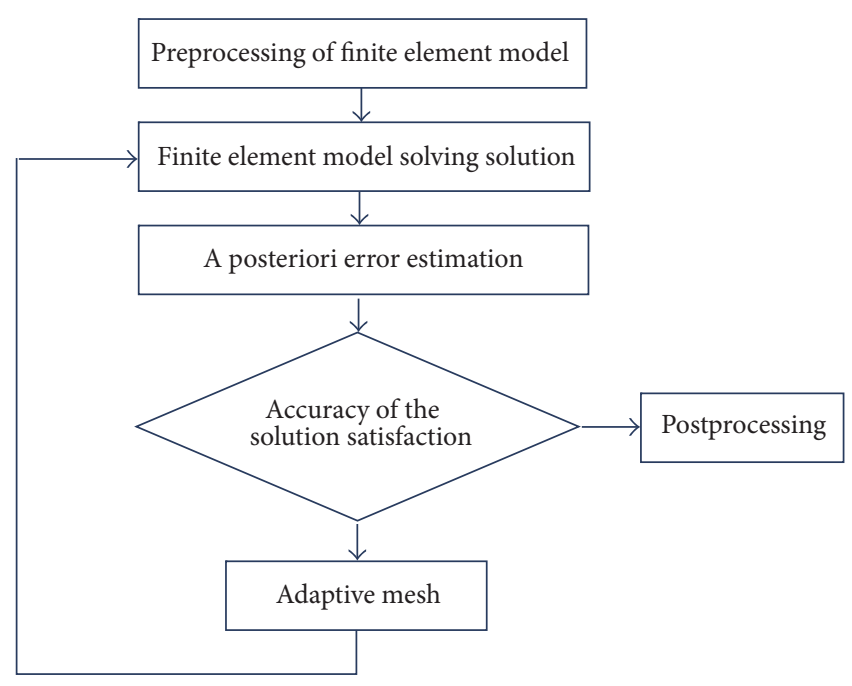

FIgURE 2: Adaptive meshing flow chart.

while the lower node stays on machining surface. This method only takes into account geometric features and fails to take into consideration the physical features in metal cutting process. The physical criterion employs physical quantities like strain, stress, temperature, and so forth at workpiece element node. Element node separation occurs when the value of physical quantity in unit exceeds the defined critical value of material property. This paper employs physical criterion in finite element analysis of wheel reprofiling and uses shear failure physical model to separate the chip from workpiece. Shear failure model is judged and used based on the value of equivalent plastic strain at integral point in the software: the element fails only when damage parameter reaches 1 .

A total of 5900 four-node thermal-coupling plane strain quadrilateral elements (abbreviated as CPE4RT) were used in the chip layer component model, separation line component, and workpiece layer component model. A total of 803 threenode plane strain thermal-coupling triangular elements (abbreviated as CPE3T) were used in the cutter workpiece model. The established thermal-mechanical coupled finite element model is shown in Figure 4.

\section{Simulation Analysis of Dynamic Cutting Form of Wheel Tread}

The extent of cutting deformation varies with cutting condition, and the resulting chip could roughly be divided into four categories: continuous chip, serrated chip (segmental chip), granular chip, and crack chip, as shown in Figure 5.

As a common kind of chip, continuous chip has a continuous appearance, where the upper surface is blanket-like, while underlying surface is smooth. Large tool rake angle, low feed rate, and high cutting speed may normally produce this kind of chip during the machining of plastic material. The cutting process with continuous chip is stable and free from significant fluctuation; the roughness of machined surface is relatively low, which offers a high surface quality. Serrated 


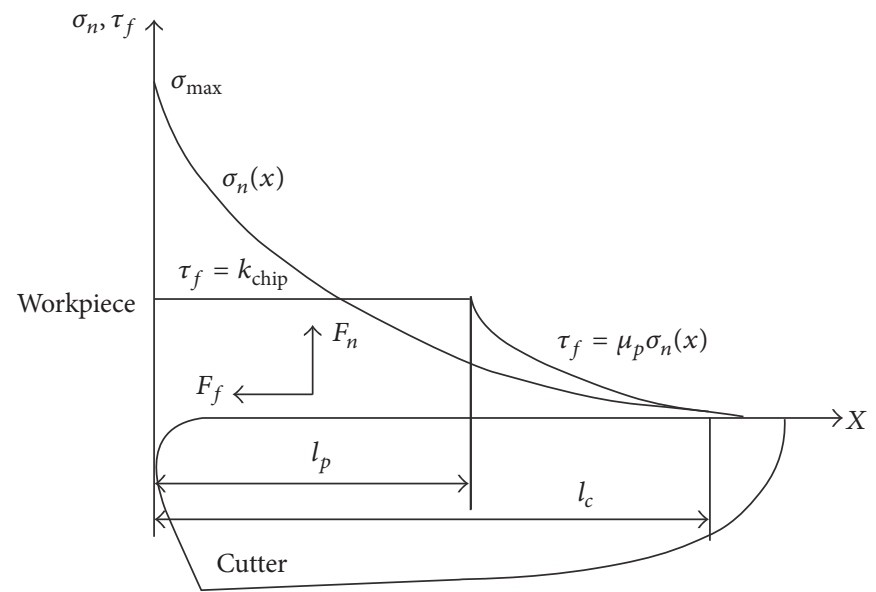

FIGURE 3: Curve of distribution of normal stress and friction stress along the cutter-chip interface.

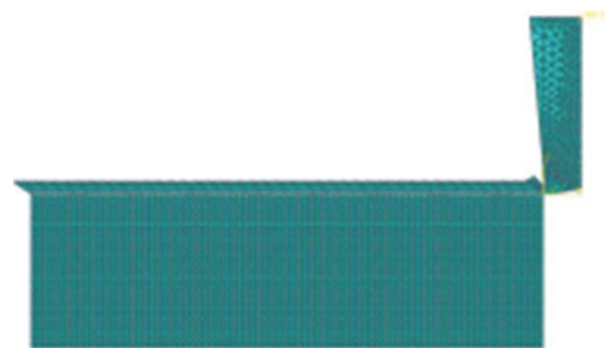

FIGURE 4: Finite element model of wheel tread reprofiling.

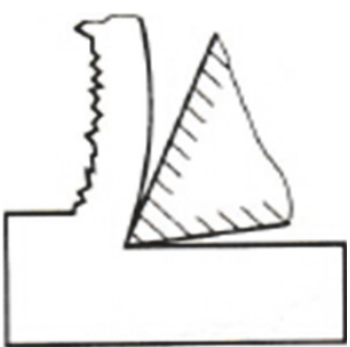

(a) Continuous chip

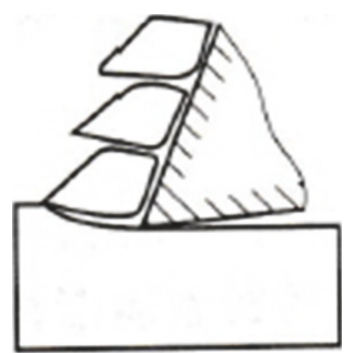

(c) Granular chip

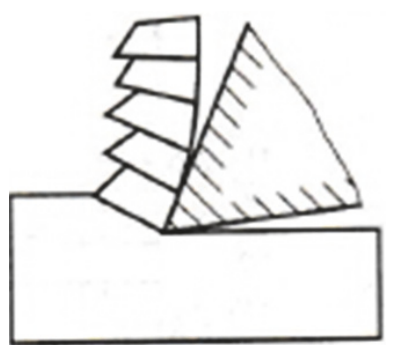

(b) Segmental chip

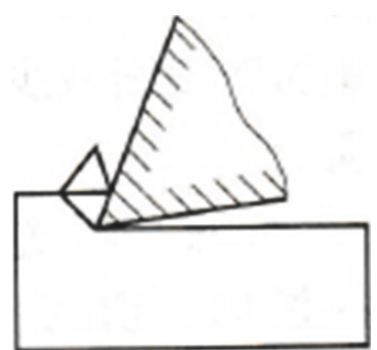

(d) Crack chip
FIgURE 5: Classification of chip.

chip and segmental chip are of the same kind and are named in different ways. Differently from continuous chip, serrated chip has a serrated back face, where crack may occur at inner arc surface sometimes. Serrated chip may come into being if the cutting thickness (back cutting depth) is great while the cutting speed is relatively low during the machining of plastic material.

Since wheel tire is made from extremely hard high carbon steel, continuous chip and serrated chip may occur frequently during wheel tread reprofiling. Figure 6 shows the numerical simulation (cutting speed $v=1.5 \mathrm{~m} / \mathrm{s}$; back cutting depth $a_{p}=0.15 \mathrm{~mm}$ ) for generation of chip from wheel tread reprofiling; Figures 6(b)-6(f) indicate the generation process of serrated chip and describe the deformation process of serrated chip through distribution cloud chart of plastic strain component, according to which the maximum plastic strain rate is observed in deformation area $I$ (i.e., the shear area) among the 3 ones during metal cutting.

Figure 6(b) shows the stage where the first sawtooth comes into being, where fierce plastic shear deformation occurs in deformation area $I$ due to the extrusion by cutter and results in the plastic instability in shear plane; hence, concentrated shear slip occurs on shear plane and brings about adiabatic shear band-the first sawtooth comes into being. Continuous serrated chip comes into being along with the continuous cutting operation.

The effect of change in back cutting depth on wheel tread chip morphology is simulated with the wheel tread chip generated at a cutting speed of $1.5 \mathrm{~m} / \mathrm{s}$ as the object of study; as shown in Figure 7, when the back cutting depth is $0.05 \mathrm{~mm}$ and $0.10 \mathrm{~mm}$, the wheel tread chip is banded; when the back cutting depth is set to $0.15 \mathrm{~mm}$, "serrated chip" occurs; the extent of sawtoothing of wheel tread chip increases with the increase in back cutting depth; when the back cutting depth is set to $0.20 \mathrm{~mm}$, more obvious sawtooth develops while the number of sawteeth decreases therewith. Figures $7(\mathrm{e})$ and $7(\mathrm{~g})$ show the actual chip collected from reprofiling site. The result above showed that back cutting depth significantly affects the chip morphology of wheel tread. The increase in back cutting depth leads to the intensification of extent of sawtoothing of wheel tread chip and the reduction in length thereof.

The law of effect of cutting speed on chip morphology is simulated with the chip obtained at a back cutting depth 


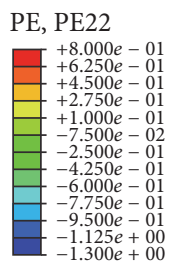

(a)

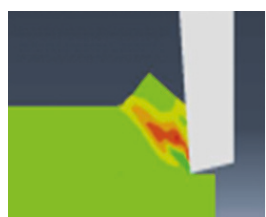

(b)

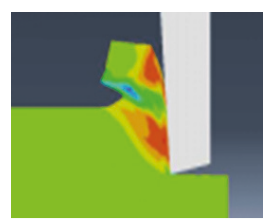

(c)

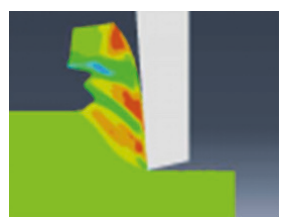

(d)

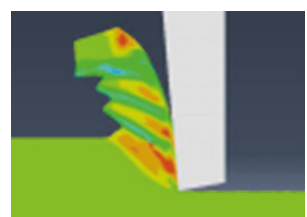

(e)

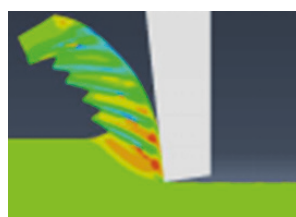

(f)

FIGURE 6: Chip forming process at wheel tread (“PE” represents plastic strain).

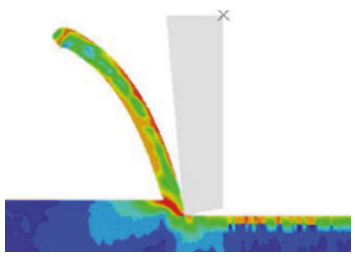

(a) $a_{p}=0.05 \mathrm{~mm}$

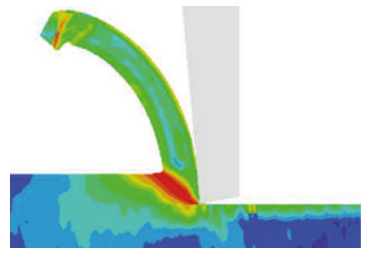

(b) $a_{p}=0.10 \mathrm{~mm}$

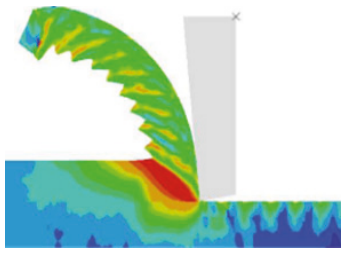

(c) $a_{p}=0.15 \mathrm{~mm}$

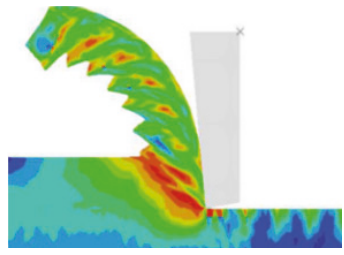

(d) $a_{p}=0.20 \mathrm{~mm}$

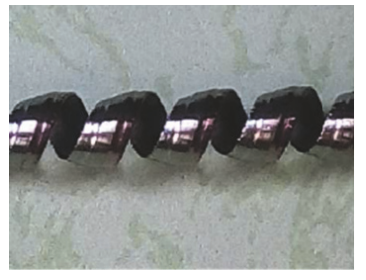

(e) Continuous chip

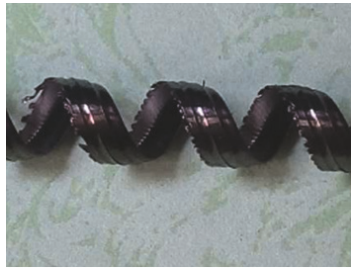

(f) Serrated chip 1

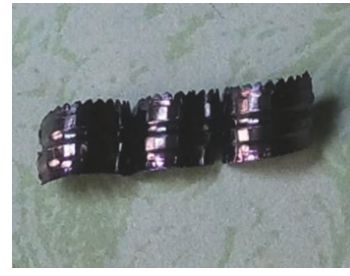

(g) Serrated chip 2

FIGURE 7: Effect of back cutting depth $a_{p}$ on wheel tread chip morphology.

of $0.05 \mathrm{~mm}$ as the object of study; Figures $8(\mathrm{a})-8(\mathrm{c})$ indicate the von Mises stress field distribution, and Figures $8(d)-8(f)$ show the actual chip from reprofiling. As shown in the figure, the increase in cutting speed results in the increase of rollup radius and the decrease in thickness of chip. The residual stress at underlying surface is much greater than that at upper surface of the chip.

\section{Analysis of Surface Machining Quality after Wheel Tread Reprofiling}

4.1. Wheel Tread Cutting Force Analysis. Cutting force is known as the reacting force of workpiece against the cutter during cutting operation; the analysis of cutting force involves the main cutting force in $X$ direction and the backward force in $Y$ direction. The variation of cutting force with time in $X$ and $Y$ directions at a cutting speed of $1.5 \mathrm{~m} / \mathrm{s}$ is shown in Figure 9.

The following conclusion could be drawn from Figure 9.

The increase in back cutting depth (cutting thickness) results in the increase of cutting force at the same cutting speed; the cutting force develops significant periodic fluctuation when back cutting depth is not less than $0.15 \mathrm{~mm}$, that is, "increase-decrease-increase" cycle. The cutting force reaches the minimum after the generation of previous sawtooth. In the meantime, the next sawtooth is beginning to take shape, while the cutting is confronted with obstacle and resistance; the cutting resistance gradually increases to a maximum when the cutting deformation of plastic deformation happens and results in the increase of shear stress on workpiece material. Since the cutter cannot release the heat generated during cutting in a timely manner, the concentration of heat in cutting area results in constant temperature rise, which leads to thermal softening of material; as a result, thermoplastic instability develops in the material near tip and brings about shear slip, at which point the cutting obstacle and resistance decrease, while the cutting force decreases therewith and reaches a minimum, when a complete sawtooth comes into being.

4.2. Wheel Tread Surface Roughness Analysis. Surface roughness, as an important indicator of surface quality, immediately determines the fineness of machined surface and has immediate impact on service life of machined part. Since the surface roughness during wheel tread reprofiling results in large part from the difference in cutting parameters, the study on law of effect of different machining parameters on surface roughness helps to identify the cutting parameters of practical machining, as shown in Figure 10.

As shown in Figure 10,

(1) the cutter may "hit out" a deep pit on machined surface when just beginning to contact the tread, thereby leading to surface quality deterioration, 


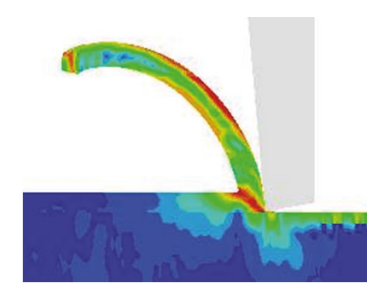

(a) $v=1.0 \mathrm{~m} / \mathrm{s}$

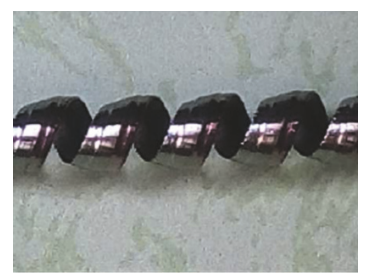

(d) Continuous chip (low speed)

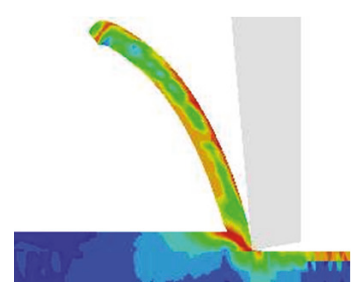

(b) $v=1.5 \mathrm{~m} / \mathrm{s}$

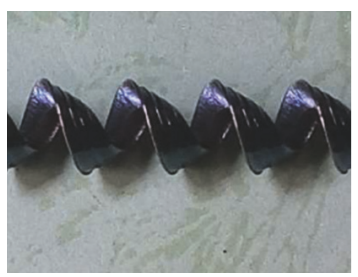

(e) Continuous chip (medium speed)

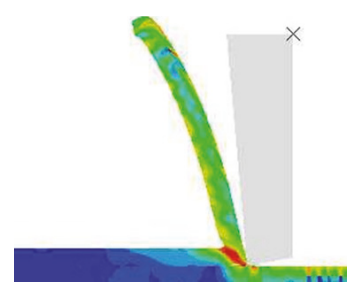

(c) $v=2.0 \mathrm{~m} / \mathrm{s}$

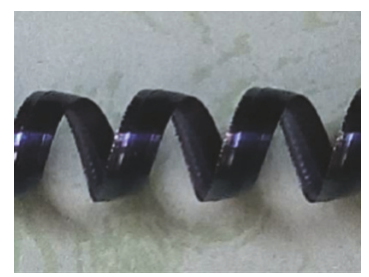

(f) Continuous chip (high speed)

FIGURE 8: Effect of cutting speed on wheel tread chip morphology.

(2) when the back cutting depth is less than or equal to $0.15 \mathrm{~mm}$, the increase in cutting speed may result in the increase of wheel tread surface roughness therewith. When the back cutting depth is set to $0.20 \mathrm{~mm}$, the surface roughness of wheel tread increases and then decreases and then increases again with the cutting speed. The key to such a law of change is that the change in elastic-plastic deformation of the contact area between cutter and workpiece is taken into account in the case of large back cutting depth. In case of low cutting speed, the large elastic-plastic deformation between cutter and workpiece brings about large value of roughness. With the increase in cutting speed, the elastic-plastic deformation between cutter and workpiece decreases, while the roughness of machined surface decreases. When the speed increases further, the vibration of lathe and cutter plays a major role in surface roughness, so the roughness increases with the intensification of vibration,

(3) when the back cutting depth is less than or equal to $0.1 \mathrm{~mm}$ during wheel reprofiling, the surface roughness of wheel tread increases gently (between $30 \%$ and $50 \%)$ at different cutting speeds, while the roughness grade is between grades 11 and 12 . When the back cutting depth increases from $0.10 \mathrm{~mm}$ to $0.15 \mathrm{~mm}$ during wheel reprofiling, the surface roughness of wheel tread increases sharply (up to 200\%) at different cutting speeds and then becomes tender with the variation of back cutting depth, but the surface roughness grade reaches grade 10. This means that back cutting depth has extremely small effect on wheel tread surface roughness within some ranges and extremely large significant effect thereon in between such ranges.

\section{Analysis of Residual Stress after Wheel Tread Reprofiling}

5.1. Analysis of Residual Stress at Wheel Tread. The remaining stress arising from the nonuniform deformation, phase change, and temperature change in the machined surface of tread in the absence of any external force is called "residual stress." Residual stress falls into residual tensile stress and residual compressive stress. The magnitude and distribution of residual stresses generated under various conditions vary depending on practical situation, and the nature (either compressive stress or tensile stress) of stress at the surface and interior of workpiece depends on the conditions that dominate; hence, specific machining conditions have to be taken into consideration for the study on distribution state of residual stress.

The residual stress cloud charts of wheel tread surface (the workpiece from a side view) under 12 different reprofiling parameters are shown in Figure 11.

As shown in Figure 11, different reprofiling parameters correspond to different residual stresses at wheel tread surface. The residual stress at wheel tread surface exhibits layered distribution at low back cutting depth; in the event of large back cutting depth, the distribution of residual stress at wheel tread surface is relatively complex: round spots develop and correspond, respectively, to the quantity of sawteeth of serrated chip; that is to say, the variation of chip morphology may bring about the change in distribution of residual stress at wheel tread surface.

\subsection{Distribution of Residual Stress in Machining Direction at the Surface and Interior of Wheel Tread. The distribution of residual stress at surface and interior of wheel tread in machining direction at a cutting speed of $1.5 \mathrm{~m} / \mathrm{s}$ and a back cutting depth of $0.05 \mathrm{~mm}$ is shown in Figure 12.}




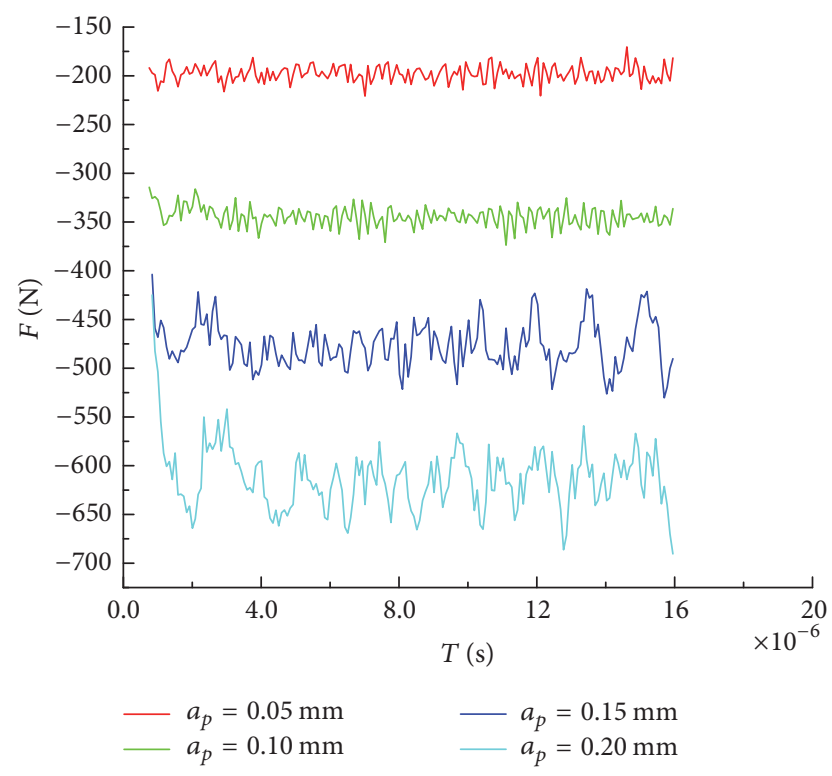

(a) The variation of cutting force with time in the $X$ direction

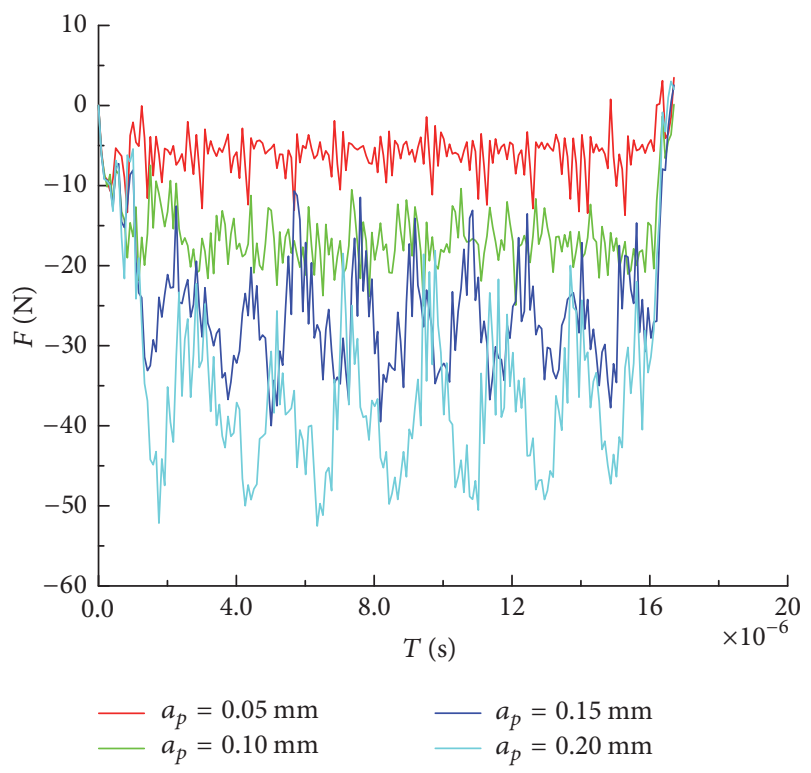

(b) The variation of cutting force with time in the $Y$ direction

FIGURE 9: Variation of cutting force at different back cutting depths.

As can be observed from Figure 12, the residual compressive stress at wheel tread surface is large (up to $521 \mathrm{MPa}$ ) when the back cutting depth for wheel reprofiling is $0.05 \mathrm{~mm}$; the distribution of residual stress at surface and interior of wheel tread in machining direction is banded; the variation is gentle, while the amplitude fluctuation is not significant. The residual compressive stress at wheel tread surface decreases (down to $329 \mathrm{MPa}$ ) when the back cutting depth for wheel reprofiling is $0.15 \mathrm{~mm}$; the residual stress at wheel tread surface exhibits periodic fluctuation and is compressive stress all the time. The residual stress at internal metal layer near the wheel tread surface also exhibits periodic fluctuation; the amplitude is significant, while tensile stress develops.
The alternative distribution of tensile stress and compressive stress impairs the surface machining quality of wheel tread.

5.3. Effect of Cutting Speed on Residual Stress at Wheel Tread Surface. The distribution of residual stress at wheel tread surface at a back cutting depth of $0.05 \mathrm{~mm}$ is shown in Figure 13.

According to Figure 13,

(1) back cutting depth has an extremely obvious effect on residual stress at machined surface of wheel tread. If the back cutting depth is less than or equal to $0.15 \mathrm{~mm}$, the residual compressive stress at machined surface of wheel tread decreases by at least $100 \mathrm{MPa}$ every time when the back cutting depth increases by $0.05 \mathrm{~mm}$,

(2) with the increase in back cutting depth, the residual compressive stress at machined surface of wheel tread decreases gradually, while the rate of decrease in stress decreases. When the back cutting depth increases from $0.15 \mathrm{~mm}$ to $0.20 \mathrm{~mm}$, the residual compressive stress at machined surface of wheel tread decreases only by $21 \mathrm{MPa}$, and this is similar to the variation of machined surface roughness of wheel tread in the case of large back cutting depth.

5.4. Distribution of Residual Stress in Depth Direction of Wheel Tread. The distribution of residual stress in depth direction of wheel tread at different back cutting depths is shown in Figure 14.

As shown in Figure 14, (1) the regularities of distribution of residual stress in depth direction of wheel tread almost remain unchanged at different back cutting depths. (2) With the increase of machined surface depth at wheel tread, the residual compressive stress decreases sharply; then tensile stress occurs and lasts for a short period of time; and then the stress fluctuates within an extremely narrow range of compressive stress. (3) When the back cutting depth is less than $0.15 \mathrm{~mm}$, the smaller the back cutting depth is, the faster the tensile stress occurs at internal metal layer of wheel tread. (4) When the back cutting depth is not less than $0.15 \mathrm{~mm}$, the larger the back cutting depth is, the faster the tensile stress occurs at internal metal layer of wheel tread, when the tensile stress value increases significantly.

\section{Conclusion}

There is growing concern about reprofiling machine, known as one of the key facilities for operation safety. Relatively high-quality tread realized through wheel reprofiling helps to extend wheelset service life and reduce wheelset maintenance cost, thereby bringing operators huge profit margin and considerable reduction in operational cost in the years to come. This paper reaches the following conclusion through simulation analysis and observation of field cutting operation:

(1) The macroscopic wheel tread chip morphology and the microcosmic roughness of machined surface at tread are associated with residual stress. 

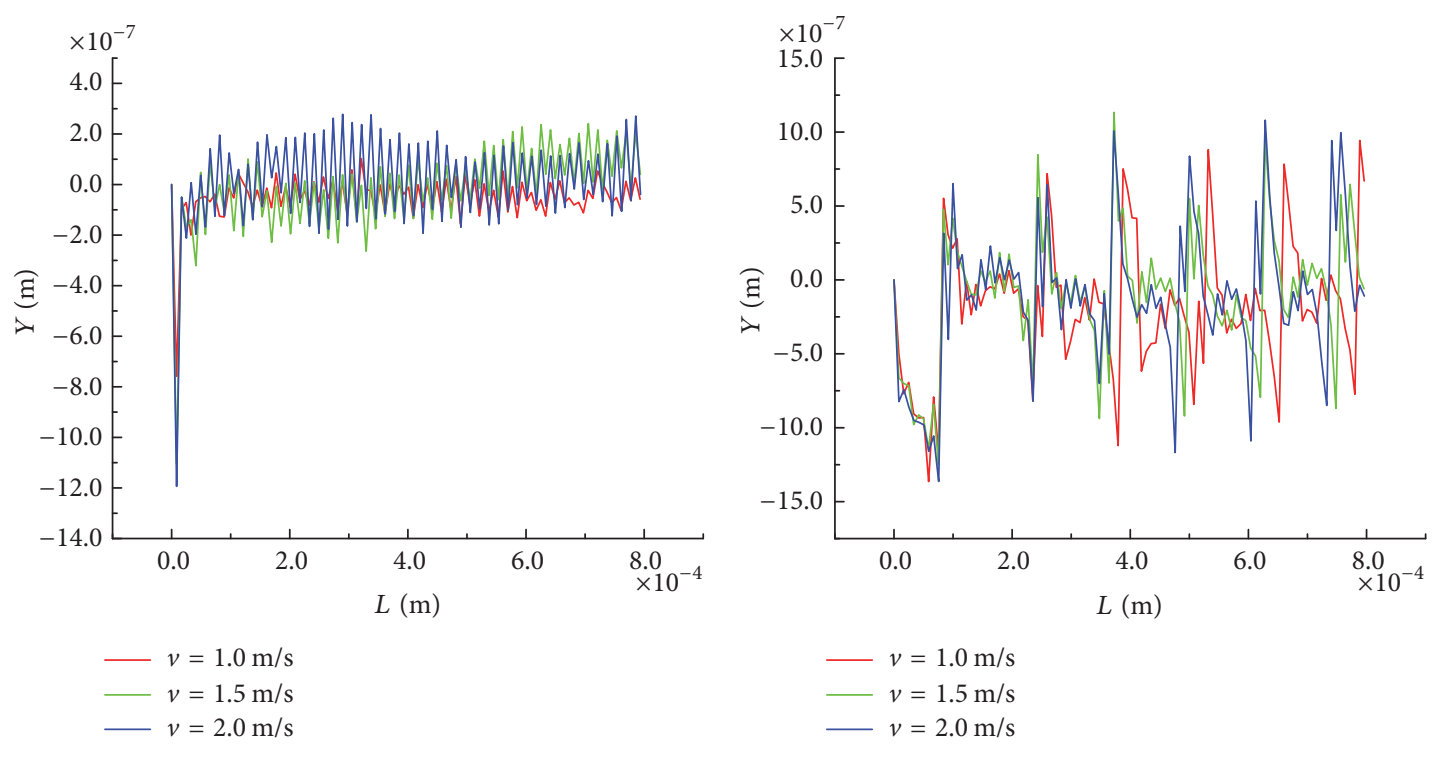

(a) Tread surface roughness $\left(a_{p}=0.05 \mathrm{~mm}\right)$

(b) Tread surface roughness $\left(a_{p}=0.20 \mathrm{~mm}\right)$
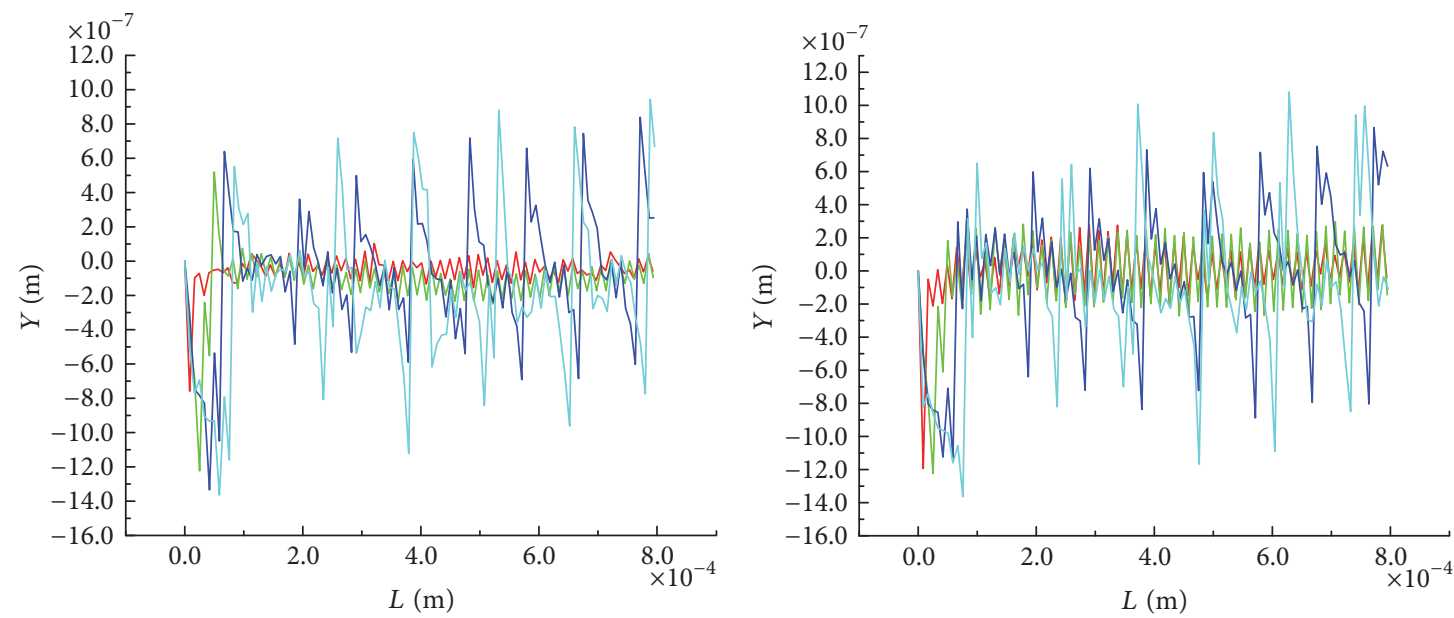

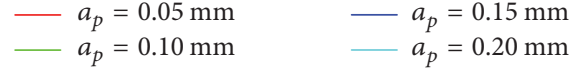

(c) Tread surface roughness $(v=1.0 \mathrm{~m} / \mathrm{s})$

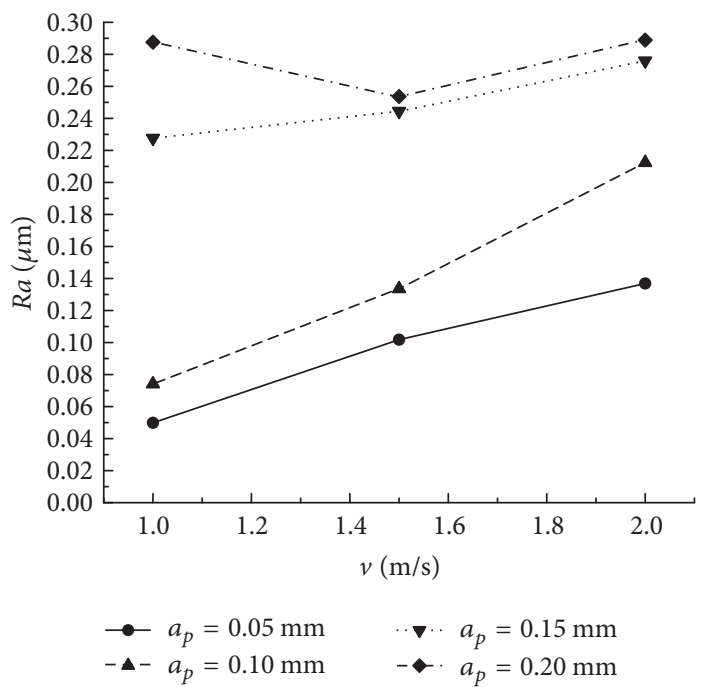

(e) The relation between cutting speed and tread surface roughness

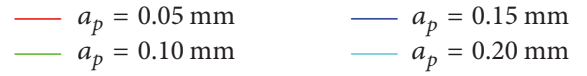

(d) Tread surface roughness $(v=2.0 \mathrm{~m} / \mathrm{s})$

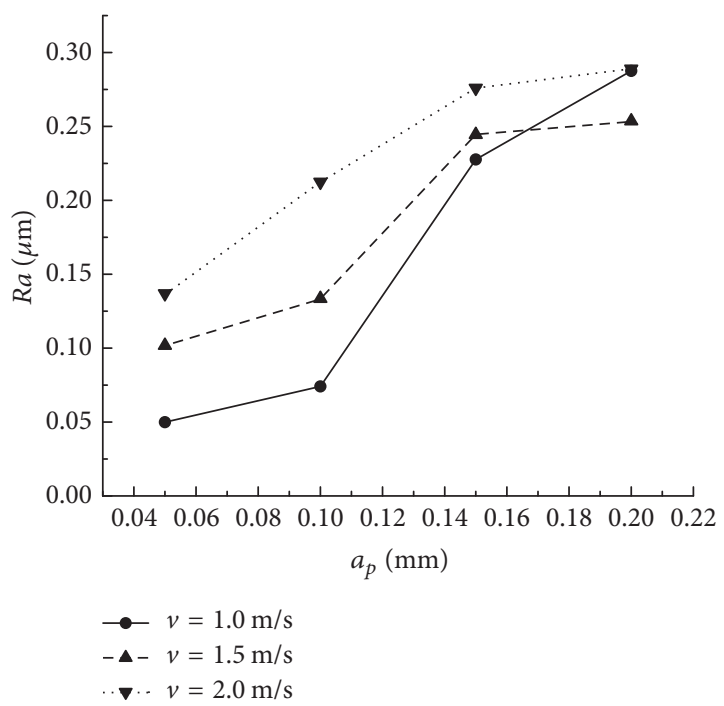

(f) The relation between back cutting depth and tread surface roughness

FIGURE 10: Effect of reprofiling parameters on wheel tread surface roughness (“ $L$ ” represents the length of the workpiece). 


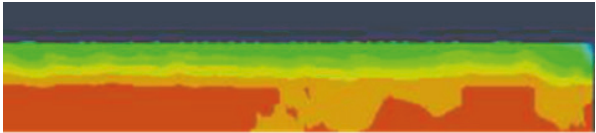

(a) $a_{p}=0.05 \mathrm{~mm} v=1.0 \mathrm{~m} / \mathrm{s}$

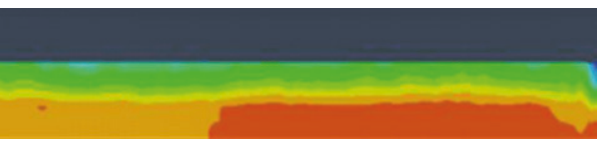

(c) $a_{p}=0.05 \mathrm{~mm} v=1.5 \mathrm{~m} / \mathrm{s}$

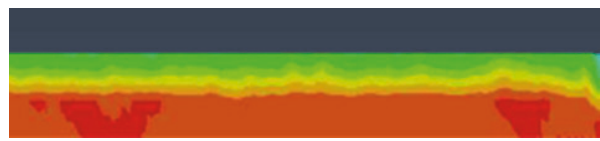

(e) $a_{p}=0.05 \mathrm{~mm} v=2.0 \mathrm{~m} / \mathrm{s}$

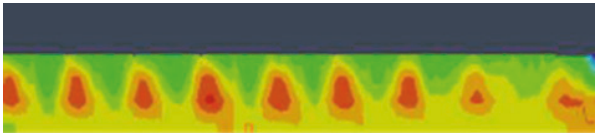

(g) $a_{p}=0.15 \mathrm{~mm} v=1.0 \mathrm{~m} / \mathrm{s}$

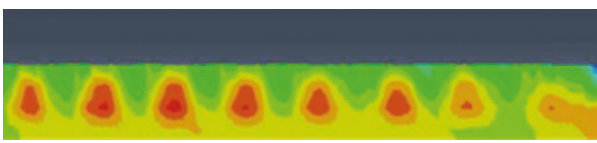

(i) $a_{p}=0.15 \mathrm{~mm} v=1.5 \mathrm{~m} / \mathrm{s}$

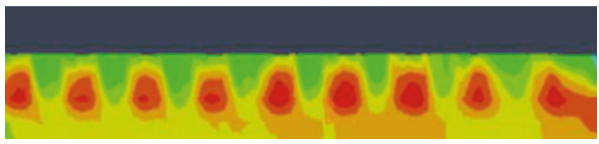

(k) $a_{p}=0.15 \mathrm{~mm} v=2.0 \mathrm{~m} / \mathrm{s}$

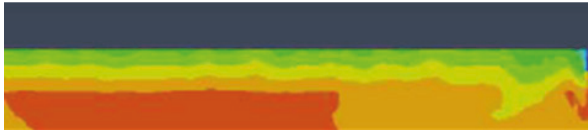

(b) $a_{p}=0.10 \mathrm{~mm} v=1.0 \mathrm{~m} / \mathrm{s}$

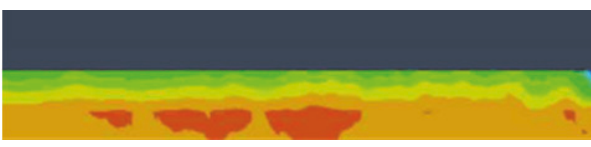

(d) $a_{p}=0.10 \mathrm{~mm} v=1.5 \mathrm{~m} / \mathrm{s}$

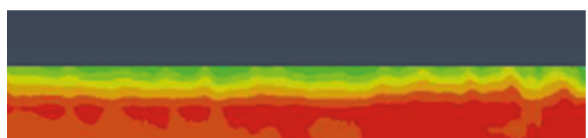

(f) $a_{p}=0.10 \mathrm{~mm} v=2.0 \mathrm{~m} / \mathrm{s}$

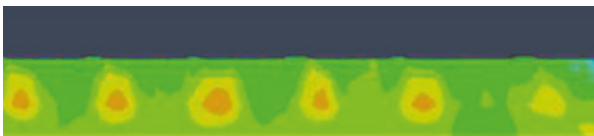

(h) $a_{p}=0.20 \mathrm{~mm} v=1.0 \mathrm{~m} / \mathrm{s}$

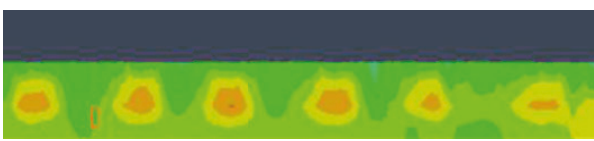

(j) $a_{p}=0.20 \mathrm{~mm} v=1.5 \mathrm{~m} / \mathrm{s}$

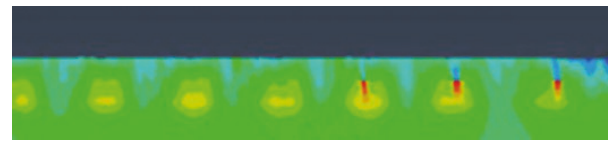

(l) $a_{p}=0.20 \mathrm{~mm} v=2.0 \mathrm{~m} / \mathrm{s}$

FIgURE 11: Residual stress cloud chart of wheel tread.

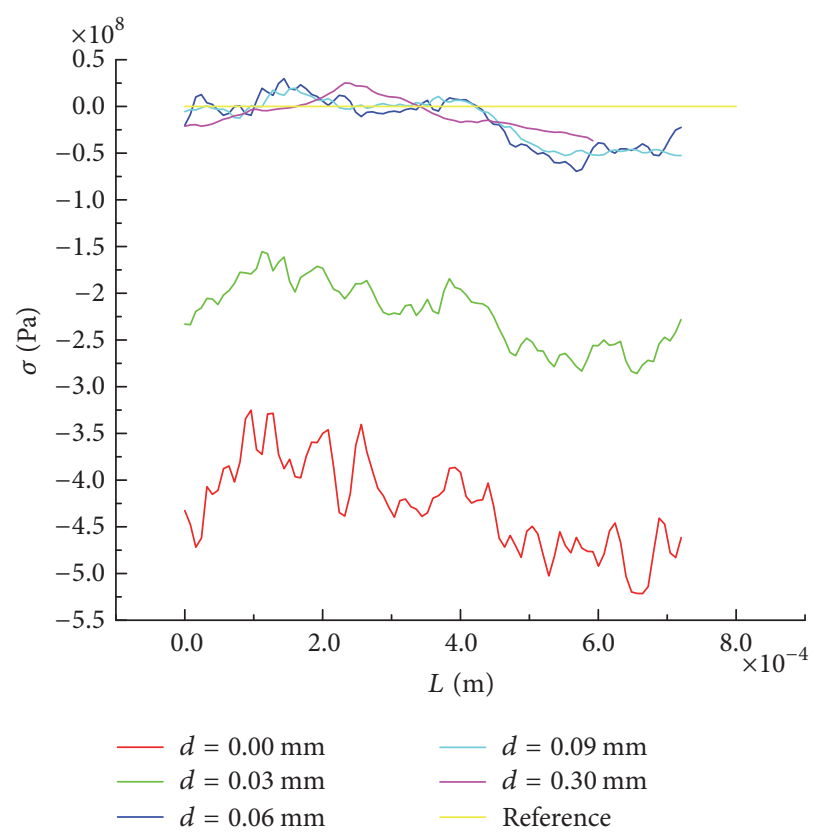

(a) $v=1.5 \mathrm{~m} / \mathrm{s} ; a_{p}=0.05 \mathrm{~mm}$

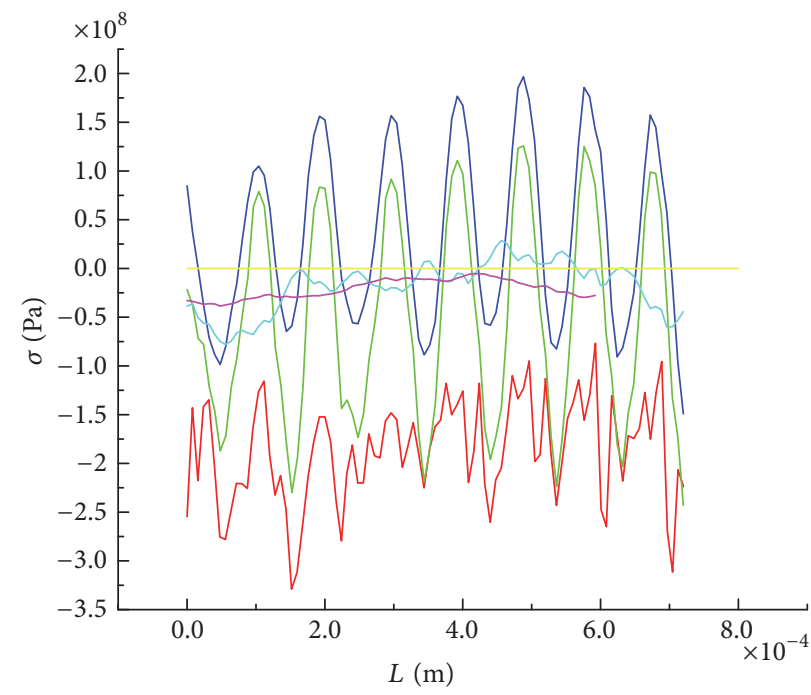
$-d=0.00 \mathrm{~mm} \quad-d=0.09 \mathrm{~mm}$
$-d=0.03 \mathrm{~mm}$
$-d=0.30 \mathrm{~mm}$
$-d=0.06 \mathrm{~mm} \quad$ Reference

(b) $v=1.5 \mathrm{~m} / \mathrm{s} ; a_{p}=0.15 \mathrm{~mm}$

FIGURE 12: Distribution of residual stress in machining direction at the surface and interior of wheel tread (" $L$ " represents the length of the workpiece). 


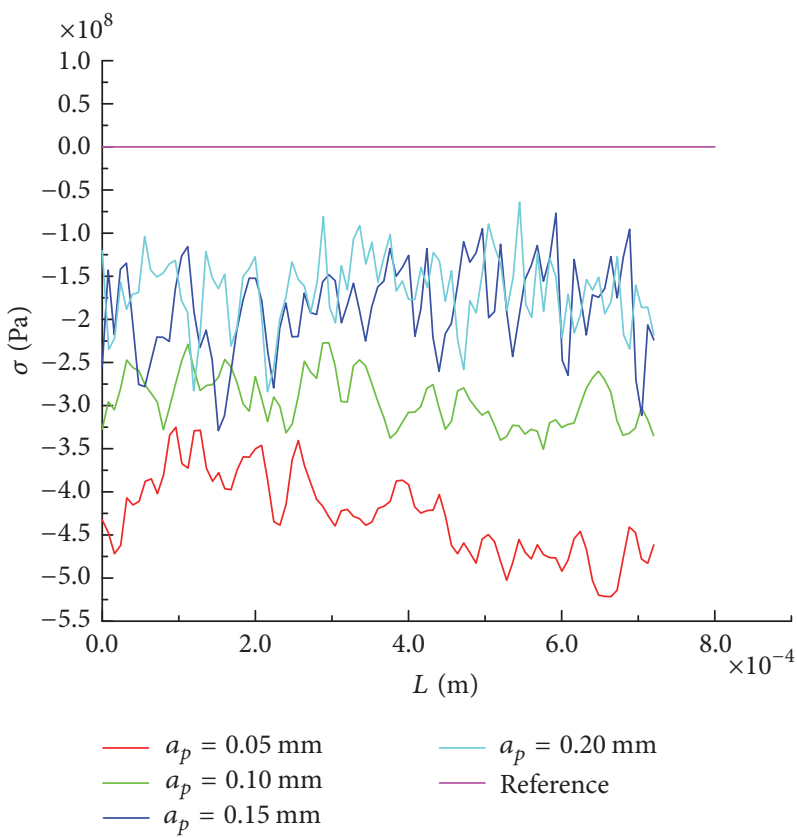

(a) Distribution of residual stress at wheel tread surface at different back cutting depths

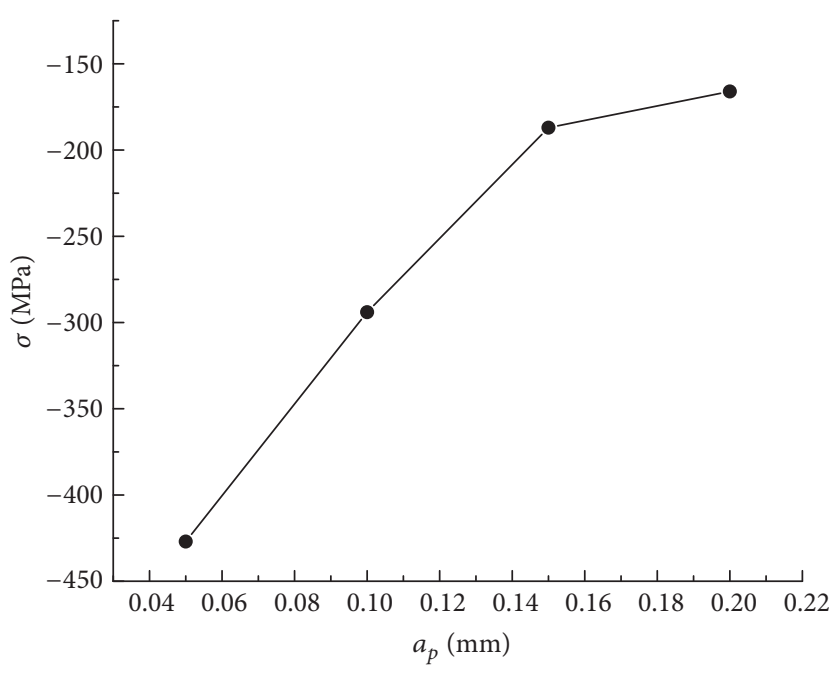

(b) Relation between back cutting depth and average residual stress at wheel tread surface

FIGURE 13: Effect of back cutting depth on residual stress at machined surface of wheel tread when the cutting speed $v$ is $1.5 \mathrm{~m} / \mathrm{s}$ (" $L$ ” represents the length of the workpiece).

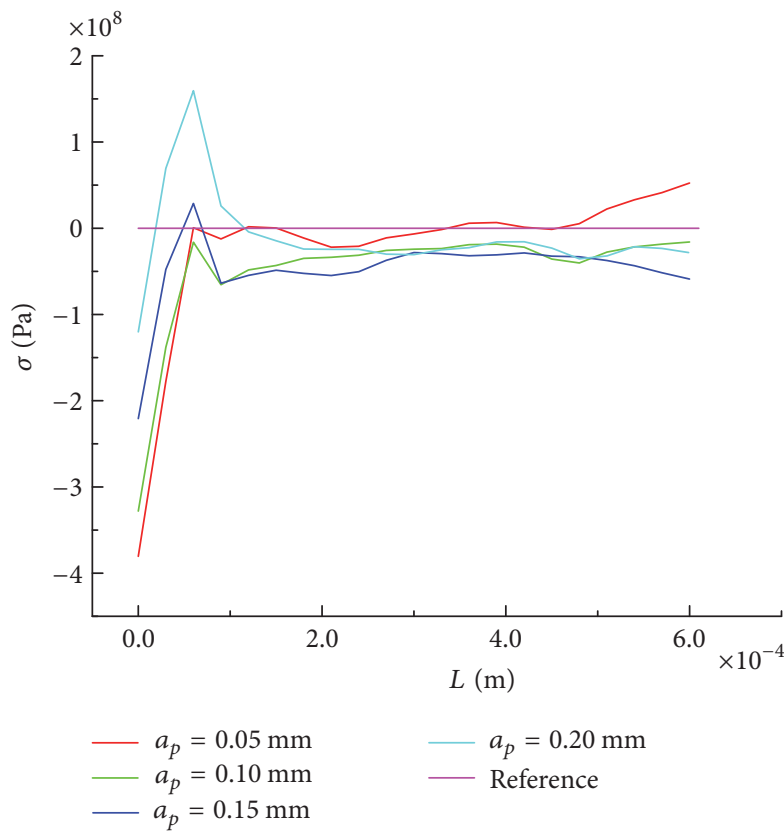

FIGURE 14: Distribution of residual stress in depth direction of wheel tread (“ $L$ ” represents the length of the workpiece).

(2) The increase in back cutting depth and cutting speed may lead to the increase of surface roughness at wheel tread and the deterioration of residual stress distribution state at machined surface.

(3) Once "serrated chip" occurs, it means that dramatic deterioration exists in the quality of machined surface at wheel tread, so it is important to avoid "serrated chip."

Since wheel tread reprofiling is an extremely complex highly thermal-mechanical coupled physical process, indepth simulation analysis shall be performed on such characterization parameter as hardness of machined surface and the residual stress of the wheel during the production process and wheel use. It is necessary to perform field experimental verification so as to improve engineering practice.

\section{Conflicts of Interest}

The authors declare that there are no conflicts of interest regarding the publication of this paper.

\section{Acknowledgments}

This work was supported by National Natural Science Foundation of China (no. 11572207 and no. 51208319), Hebei Provincial Natural Science Foundation of China (no. E2015210099 and no. E2016210131), and Key Project of Hebei Educational Committee of China (no. ZD2015037 and no. ZD2014084).

\section{References}

[1] G. W. Yang, Y. J. Wei, G. L. Zhao et al., "Current research progress in the mechanics of high speed rails," Advances in Mechanics, vol. 45, pp. 217-460, 2015.

[2] F. Braghin, S. Bruni, and F. Resta, "Wear of railway wheel profiles: A comparison between experimental results and a 
mathematical model," Vehicle System Dynamics, vol. 37, pp. 478489, 2003.

[3] W. J. Ren, D. B. Cui, L. Li, and J. Su, "Influence of wheel reprofiling on wheel-rail profile matching performance," Lubrication Engineering, vol. 40, no. 5, pp. 16-21, 2015.

[4] X. Q. Dong, Y. M. Wang, Z. S. Ren, L. D. Wang, and H. Y. Liu, "Design and application of thin flange wheel tread profiles for CRH3C EMUs," Tiedao Xuebao/Journal of the China Railway Society, vol. 36, no. 2, pp. 11-17, 2014.

[5] X. K. Xiao, "Economic analysis of wheel lathing in metro vehicles," Urban Mass Transit, vol. 5, pp. 91-92, 2016.

[6] B. Zhang, Z. Lu, and C. Tang, "Wheel reprofiling of high-speed EMU based on multi-objective optimization strategy," Tongji Daxue Xuebao/Journal of Tongji University, vol. 41, no. 3, pp. 437-442, 2013.

[7] T. V. Chien, F. Li, Z. Qi, and J. J. Ding, "Processing method of locomotive wheel wear statistical data and prediction model of turning period," Tiedao Xuebao/Journal of the China Railway Society, vol. 37, no. 12, pp. 14-19, 2015.

[8] F. Kouyuki, "Wheel tread management and its planned and economic turning," Foreign Locomotive \& Rolling Stock Technology, no. 4, pp. 13-17, 1995.

[9] O. Miyabitaka, "Research of the determination of turning allowance for wheel tread," Foreign Locomotive \& Rolling Stock Technology, no. 1, pp. 14-18, 2009.

[10] H. T. Liu, Z. S. Lu, and Y. Z. Sun, "Status and development of residual stress on the surface in the cutting," Aviation Precision Manufacturing Technology, vol. 44, no. 1, 2008.

[11] Z. Q. Wang and C. F. Liu, "Literature review of residual stress on the surface in cutting," Aeronautical Manufacturing Technology, vol. 6, pp. 26-30, 2016.

[12] H. Sasahara, T. Obikawa, and T. Shirakashi, "FEM analysis of cutting sequence effect on mechanical characteristics in machined layer," Journal of Materials Processing Technology, vol. 62, no. 4, pp. 448-453, 1996.

[13] J. W. Seo, B. C. Goo, J. B. Choi, and Y. J. Kim, "Effects of metal removal and residual stress on the contact fatigue life of railway wheels," International Journal of Fatigue, vol. 30, no. 10-11, pp. 2021-2029, 2008.

[14] S. Hiroyuki, O. Toshiyuki, and S. Takahiro, "Prediction model of surface residual stress with in a machined surface by combinng two orthogonal plane models," International Journal of Machine Tools \& Maufacture, vol. 44, no. 7-8, pp. 815-822, 2004.

[15] R. M. Nejad, "Using three-dimensional finite element analysis for simulation of residual stresses in railway wheels," Engineering Failure Analysis, vol. 45, pp. 449-455, 2014.

[16] R. M. Nejad, K. Farhangdoost, and M. Shariati, "Numerical study on fatigue crack growth in railway wheels under the influence of residual stresses," Engineering Failure Analysis, vol. 52, pp. 75-89, 2015.

[17] M. B. Paul and B. Adam, "Residual stresses in railway wheels and their effect on damage rates through the life of a wheel," in Proceedings of the Computing and Engineering Annual Researchers' Conference 2013 (CEARC '13), University of Huddersfield, Huddersfield, Yorkshire, England, 2013.

[18] E. Usui, K. Maekawa, and T. Shirakashi, "Simulation analysis of built-up edge formation in machining of low carbon steel," Bulletin of the Japan Society of Precision Engineering, vol. 15, no. 4, pp. 237-242, 1981.
[19] J. S. Strenkowski and K. Moon, "Finite Element Prediction of Chip Geometry and Tool/Workpiece Temperature Distributions in Orthogonal Metal Cutting," Journal of Engineering for Industry, vol. 112, no. 4, p. 313, 1990.

[20] L. Zhang, "On the separation criteria in the simulation of orthogonal metal cutting using the finite element method," Journal of Materials Processing Technology, vol. 89-90, pp. 273278, 1999.

[21] Y. Sun, H. Liu, and Z. Lu, "Finite element simulation and experimental research of residual stresses in the cutting based on the coupled thermo-mechanical model," Jixie Gongcheng Xuebao/Journal of Mechanical Engineering, vol. 47, no. 1, pp.187193, 2011.

[22] K. Filipowicz, W. Biedunkiewicz, M. Krolikowski, and D. Grzesiak, "Machining of resilient wheelsets on wheel-turning lathes," in DAAAM International Scientific Book 2010, 2010.

[23] Z. Tian, "Economic selection of milling cutters for wheel tread reprofiling of CRH2 type EMU," China High-tech Enterprise, vol. no.18, pp. 102-103, 2014.

[24] D. Cioboata, A. Abalaru, D. Stanciu, L. Cristian, I. Ghionea, and S. Szekely, "Technological system for profiling/re-profiling railway wheel sets," Optics \& Mechatronics, no. 47, pp. 79-85, 2015.

[25] A. R. Andrade and J. Stow, "Assessing the efficiency of maintenance operators: a case study of turning railway wheelsets on an under-floor wheel lathe," Proceedings of the Institution of Mechanical Engineers, Part O: Journal of Risk and Reliability, vol. 231, no. 2, pp. 155-163, 2017.

[26] N. N. Zorev, "Inter- relations hip between shear processes occurring along tool face and shear plane in metal cutting," in International Research in Production Engineering, pp. 42-49, New York: ASME, 1963. 

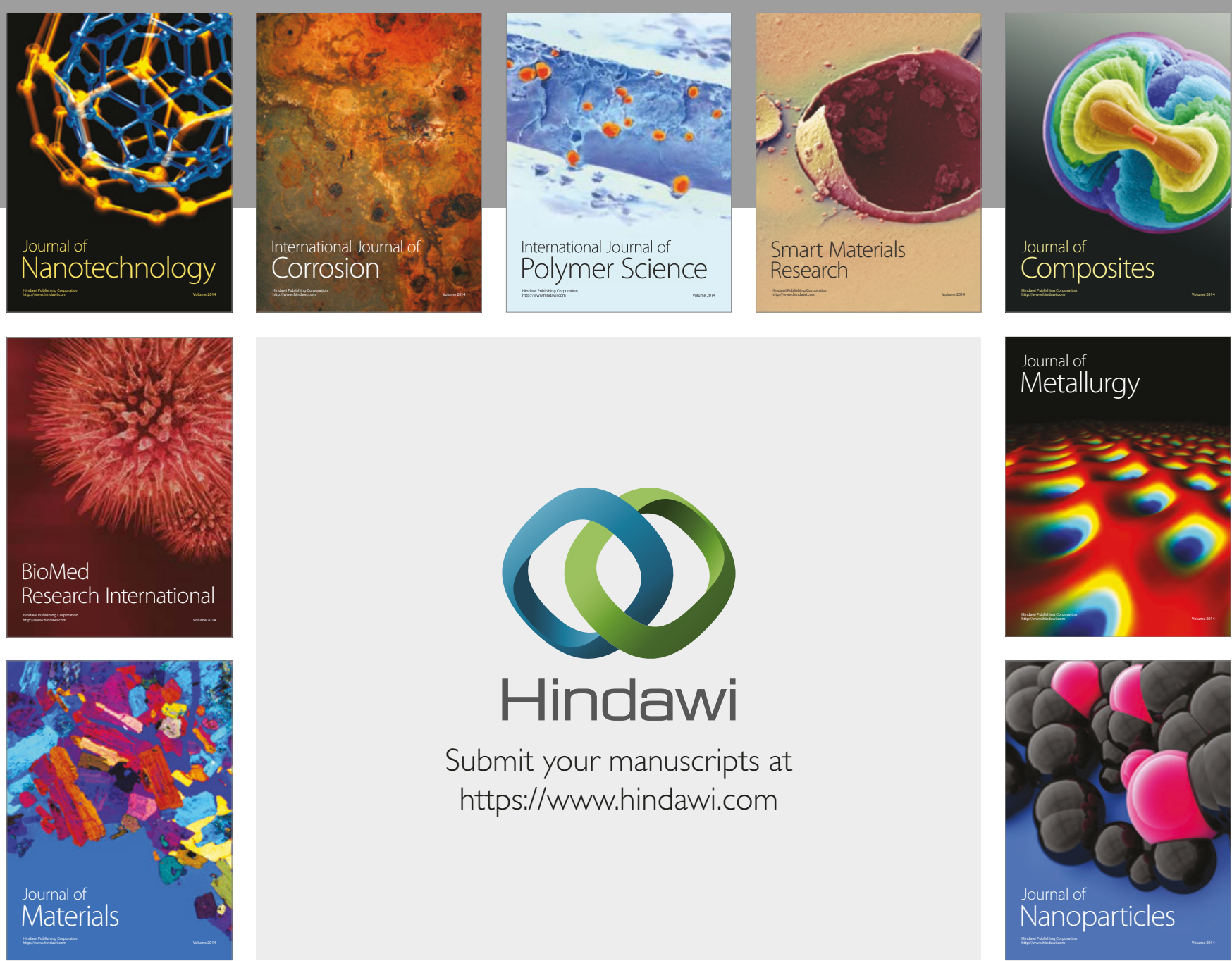

\section{Hindawi}

Submit your manuscripts at

https://www.hindawi.com
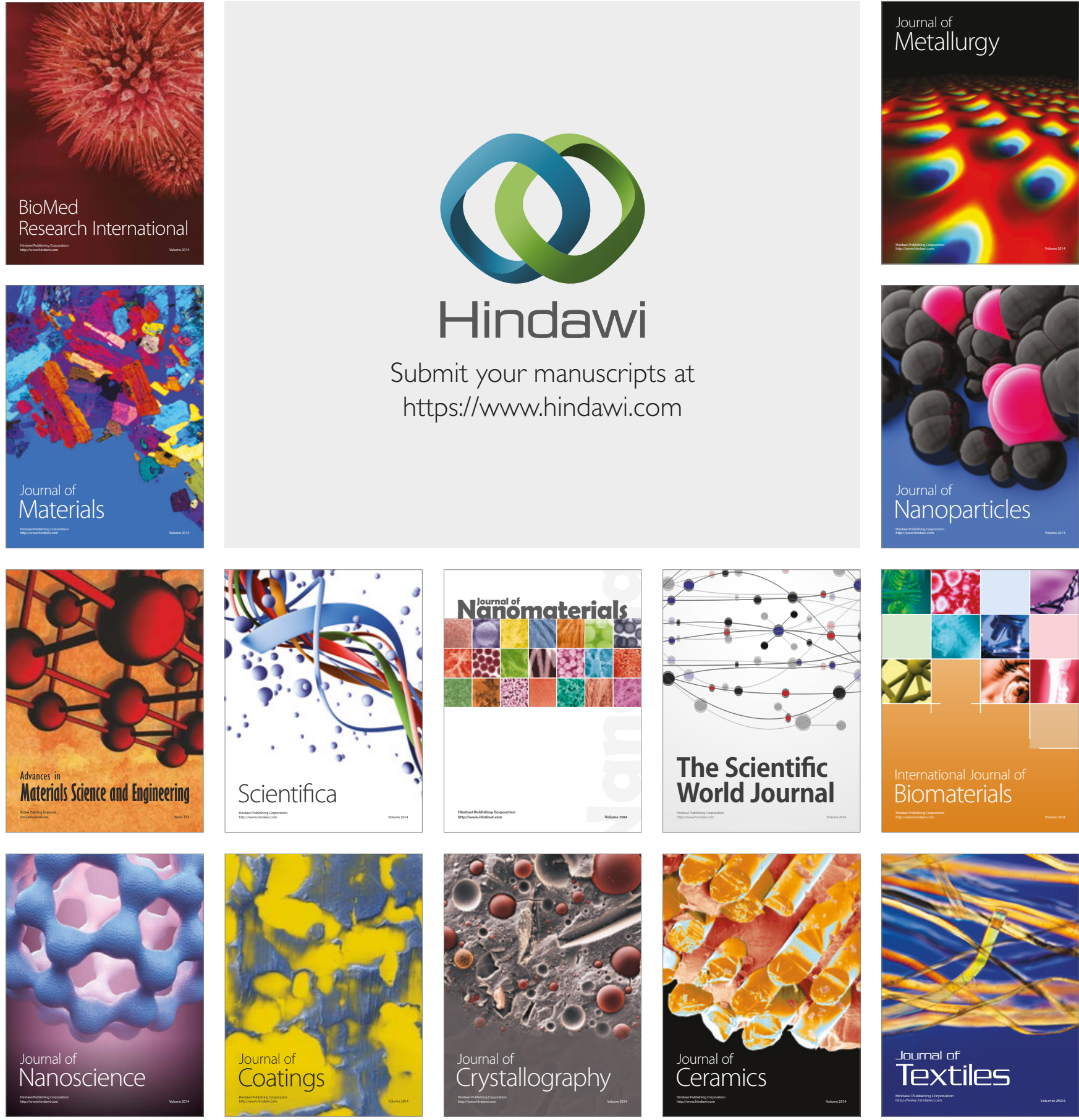

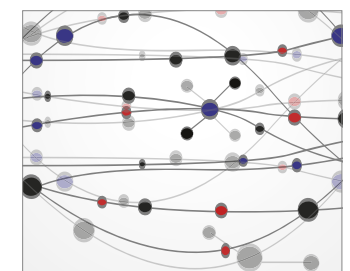

The Scientific World Journal
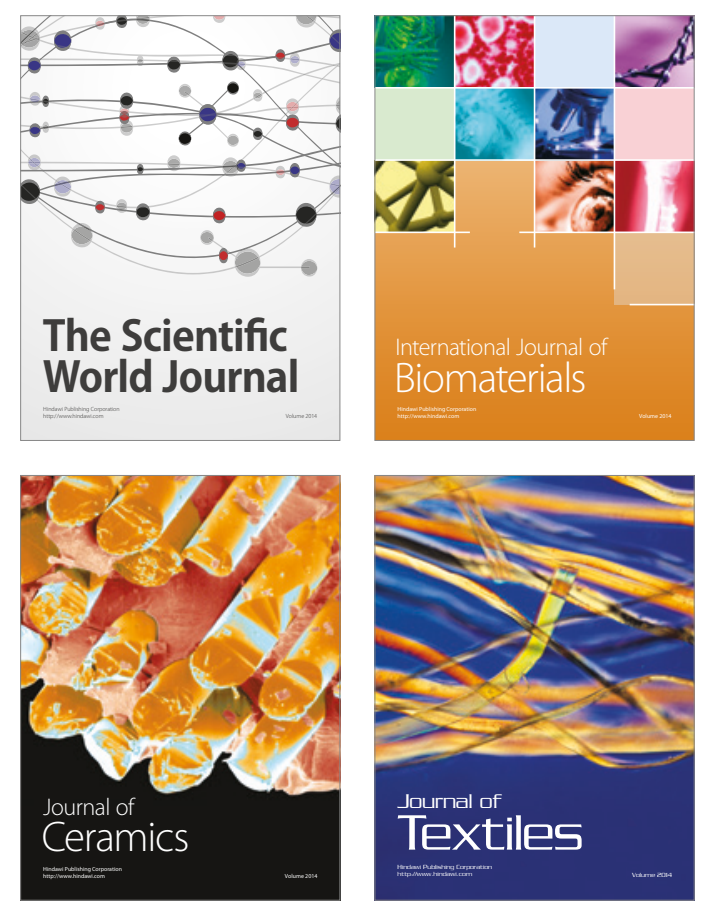